\title{
PHYLOGENETIC STUDY OF ERIOBOTRYA (ROSAGEAE) BASED ON COMBINED CPDNA PSBA-TRNH AND ATPB-RBCL MARKERS
}

\author{
Idrees $\mathbf{M}^{1,2}$, Wang Hui ${ }^{1}$, Mitra $\mathrm{LP}^{2}$, Zhang $\mathrm{ZY}^{1} \& \mathrm{Gao} \mathrm{XF}^{2, *}$ \\ ${ }^{1}$ College of Life Science, Neijiang Normal University, Neijiang 641000, Sichuan, China \\ ${ }^{2}$ CAS Key Laboratory of Mountain Ecological Restoration and Bioresource Utilization E Ecological Restoration and \\ Biodiversity Conservation Key Laboratory of Sichuan Province, Chengdu Institute of Biology, Chinese Academy of Science, \\ P.O Box 416, Chengdu 61004, China \\ *xfgao@cib.ac.cn \\ Submitted July 2020; accepted December 2020
}

\begin{abstract}
The phylogenetic relationships of Eriobotrya were examined based on cpDNA psbA-trnH and atpB-rbcL markers using 21 names with $M$. germanica, $P$. beauverdiana and $R$. indica as an outgroup. The results revealed that the sequencing analysis contained around 841 bp aligned DNA characters, where 81 bp were variables and $42 \mathrm{bp}$ were informative polymorphic sites. Further analysis showed that the phylogeny tree divided the species of Eriobotrya into 4 clades. Eriobotrya bengalensis, E. bengaensis var. angustifolia and E. obovata were closely related and formed clade A. E. deflexa, E. fragrans and E. seguinii clustered into clade B. E. japonica, E. malipoensis and E. $\times$ daduheensis clustered into clade C and E. fusca, E. cavaleriei, E. tengyuehensis, E. condaoensis, E. serrata, E. hookeriana, E. petiolata, E. salwinensis and E. elliptica were clustered into clade D. The present study concluded that future research with more taxa and the use of more DNA barcoding markers may be needed to resolve the complete phylogeny and evolution of Eriobotrya.
\end{abstract}

Keywords: Eriobotrya, classification, DNA barcoding markers, sequence analysis, polymorphic sites

\section{INTRODUCTION}

The plant genus Eriobotrya Lindley (Lindley 1821), belongs to the family Rosaceae (Potter et al. 2007), tribe Maleae and subtribe Malinaeals (Sun et al. 2018). The genus includes more than 30 names, of these 21 names were recorded in China (Yang et al. 2005), whereas the remaining names were record in southeast Asia (Laos, Malaysia, Myanmar and Thailand), southern Japan, and the Himalayas (Bhutan, India and Nepal) (Vidal 1965). Further research work is necessary to evaluate the evolution and origin of Eriobotrya and to further exploit Eriobotrya species for pharmaceutical and industrial purposes.

The generic circumscription of Eriobotrya species were primarily discussed based on morphological characters, such as leaf blade abaxially tomentose and without tomentose (Yu 1974), autumn-flowering group and winterflowering group (Zhang et al. 1990), leaf size, style number and stamens (Yang et al. 2007, Yang et al. 2017) and numerical taxonomy (Zhang et al. 2017).
The systematic treatments of Eriobotrya based on molecular analysis were reported from broader studies on the family Rosaceae (Potter et al. 2007). In a previous study, Xie et al. (2007) analysed the phylogenetic relationships based on ISSR markers and concluded that E. japonica was closely related to E. prinoides var. daduheensis, E. maliopensis. E. deflexa, and E. deflexa var. koshunensis. E. elliptica was genetically distant and made a separate clade. E. henryi, E. serrata and E. seguinii were closely similar to each other. In addition, they further concluded that E. kwangsiensis was a distinct species. Yang et al. (2009), examined the phylogenetic relationships of Eriobotrya species using amplified fragment length polymorphism (AFLP) markers revealed that the species were grouped into 3 main clusters. Cluster I consisted of $E$. henryi and E. seguinii, Cluster II consisted of E. elliptica and E. serrata, and Cluster III consisted of E. japonica and E. maliopensis. Furthermore, E. prinoides and E. prinoides var. daduheensis, E. cavaleriei and E. fragrans were closely related, 
and E. deflexa, E. deflexa var. koshunenis were closely related and indicating that substantial genetic variations were found in Eriobotrya. Li et al. (2009) evaluated the phylogenetic study of Eriobotrya species based on nrDNA ITS sequence revealed that the genus Eriobotrya formed a monophyletic group and genetically close to Rhaphiolepis indica than Photinia serrulata and concluded that $E$. cavaleriei treated to be a variety of $E$. fragrans as previously reported by Yang et al. (2005). Li et al. (2011) examined the preliminary phylogenetic study based on chloroplast rbcL and trnL-trnF sequences revealed that $E$. seguinii was the primitive taxa in the genus Eriobotrya and concluded that cpDNA sequences could not resolve certain relationships of Eriobotrya species due to the limitations in evolution. Yang et al. (2012) analysed the phylogenetic study on the genus Eriobotrya based on nrDNA adh sequences revealed that E. japonica, E. prinoides, E. prinoides var. daduheensis and E. elliptica were closely related to each other but E. malipoensis was genetically separated from other species. Furthermore, they concluded that $E$. cavaleriei could be classified as a variety of $E$. fragrans.

Taxon relationships and classification of the genus Eriobotrya are debatable and unclear. Several early treatments for species relationships and classification were based on cultivars and few wild species of Eriobotrya. Thus, the present study aimed to evaluate the phylogenetic relationships of the genus Eriobotrya based on combined cpDNA psbA-trnH and atpB-rbcL markers from southeast Asia and Himalaya regions.

\section{MATERIALS AND METHODS}

\section{Plant materials}

A total of 21 names including eighteen taxa of Eriobotrya while Mespilus germanica, Rhaphiolepis indica and Photinia beauverdiana were selected as an outgroup in the present study (Table 1).

\section{Genomic DNA extraction and PGR amplifications}

Plant genomic DNA extraction kit was used to extract the genomic DNA from dried specimens. The two chloroplast regions; psbA-trnH and atpB-rbcL (Savolainen et al. 1994, Sang et al. 1997) were used for amplification. Polymerase chain reactions (PCR) were carried out in a $25 \mu \mathrm{l}$ tubes containing $1 \mu \mathrm{l}$ of genomic DNA (20-100 ng), $1 \mu \mathrm{l}$ of each primer pair $(10 \mathrm{mM}), 0.5 \mu \mathrm{l}$ of dNTP Mix $(10 \mathrm{mM}), 2.5 \mu \mathrm{l}$ of $10 \mathrm{X} \mathrm{MgCl}_{2}$ buffer, $5 \mathrm{U}^{-1} \mathrm{l}^{-1}$ of DNA polymerase and sterile water. A thermo cycler was used to performed PCR and amplification of the region. The process consisted of initial denaturation for $5 \mathrm{~min}$ at $94^{\circ} \mathrm{C}$ and at 35 cycles for $1 \mathrm{~min}$ at $94^{\circ} \mathrm{C}$ and followed by annealing temperature for psbA-trnH at $58^{\circ} \mathrm{C}$ for $1 \mathrm{~min}$ and for atpB-rbcL at $72{ }^{\circ} \mathrm{C}$ for $1.5 \mathrm{~min}$. The final extension step was conducted at $72{ }^{\circ} \mathrm{C}$ for $7 \mathrm{~min}$ and later maintained at $4{ }^{\circ} \mathrm{C}$. The PCR product was gel-separated by $1 \%$ Agarose TAE buffers and the sample was finally sequenced.

\section{Sequences information and alignment}

Closet sequences and others published sequences of Eriobotrya names were retrieved from National Center for Biotechnology Information and included in the final datasets for phylogenetic analysis (Table 1). Mespilus germanica, Rhaphiolepis indica and Photinia beauverdiana were designated as an outgroup for rooting purposes following Campbell et al. (2007). ClustalW software was used for sequences alignment (Larkin et al. 2007) and manually edited using Bioedit sequence alignment editor v 7.0.5.3 (Hall 1999).

\section{Data analysis}

The best-fit DNA substitution model for each dataset with default setting was performed using MEGA 6 software and the parameter values were determined by Alkaike Information Criterion. Phylogenetic analysis was conducted using Maximum Likelihood (ML) method and selected T92 model with gaps were treated as missing data using MEGA 6 software (Tamura et al. 2013). Support values were assessed using the bootstrap option with 1000 replicates.

\section{RESULTS}

\section{Analysis of cpDNA markers}

The combined cpDNA datasets were composed of 21 names and the sequencing analysis comprised $841 \mathrm{bp}$ aligned DNA characters, of these 81 bp were variables and $42 \mathrm{bp}$ were informative polymorphic sites. 
Table 1 List of taxa, locality, vouchers, herbaria and GenBank accession numbers used in the present study

\begin{tabular}{|c|c|c|c|c|}
\hline \multirow[t]{2}{*}{ Taxon } & \multirow[t]{2}{*}{ Locality } & \multirow[t]{2}{*}{ Vouchers } & \multirow[t]{2}{*}{ Herbarium } & \multirow{2}{*}{$\begin{array}{l}\text { GenBank } \\
\text { Accession No. } \\
\begin{array}{l}\text { PsbA-trnH } \\
\text { atpB-rbcL }\end{array}\end{array}$} \\
\hline & & & & \\
\hline E. bengalensis (Roxb.) Hook. f. & China & 0298946 & IBSC & Present study \\
\hline E. bengalensis var. angustifolia Card. & Yunnan, China & 0298949 & IBSC & Present study \\
\hline E. cavaleriei (H.Lévl.) Rehd. & Guangxi, China & 0299011 & $\mathrm{PE}$ & Present study \\
\hline $\begin{array}{l}\text { E. condaoensis X.F.Gao, M.Idrees \& } \\
\text { T.V.Do }\end{array}$ & Vietnam & VNMN_CN 633 & CDBI & Present study \\
\hline E. $\times$ daduheensis Liao et al. & Sichuan, China & 00004578 & $\mathrm{PE}$ & Present study \\
\hline E. deflexa (Hemsl.) Nakai & Taiwan & 01568202 & $\mathrm{PE}$ & Present study \\
\hline E. elliptica Lindl. & Nepal & 0652620 & KUN & Present study \\
\hline E. fragrans Champ. ex Benth. & Guangdong, China & 0299116 & IBSC & Present study \\
\hline E. fusca K.Kuan & Yunnan, China & 00799408 & $\mathrm{PE}$ & Present study \\
\hline E. hookeriana Decne. & Bhutan & 1575791 & $\mathrm{PE}$ & Present study \\
\hline E. japonica (Thunb.) Lindl. & Sichuan, China & 00799571 & $\mathrm{PE}$ & Present study \\
\hline E. malipoensis K.C.Kuan & Yunnan, China & 0299390 & IBSC & Present study \\
\hline E. obovata W.W.Sm. & Yunnan, China & - & $\mathrm{PE}$ & Present study \\
\hline E. petiolata Hook. f. & Bhutan & 01639921 & $\mathrm{PE}$ & Present study \\
\hline E. salwinensis Hand.-Mazz. & Yunnan, China & 607631 & KUN & Present study \\
\hline E. seguinii (H.Lév.) Card. ex Guill. & Yunnan, China & - & - & FJ571507 c \\
\hline E. serrata Vidal & Yunnan, China & 1227861 & KUN & Present study \\
\hline E. tengyuehensis W.W.Sm. & Yunnan, China & - & - & FJ796915 c \\
\hline Mespilus germanica L. & Chicago, USA & M645-80 & - & $\begin{array}{l}\text { ab } H Q 427046.1^{\mathrm{a}} \\
{ }^{\mathrm{ab}} \mathrm{HQ} 427046.1^{\mathrm{b}}\end{array}$ \\
\hline Photinia beauverdiana C.K Schneid. & GenBank & $1733-80 \mathrm{~A}$ & - & $\begin{array}{l}{ }^{\text {ab }} H Q 427047.1^{\mathrm{a}} \\
{ }^{\text {ab }} H Q 427046.1^{\mathrm{b}}\end{array}$ \\
\hline Rhaphiolepis indica (L.) Lindl. & GenBank & & - & $\begin{array}{l}{ }^{\mathrm{ab}} \mathrm{HQ} 427046.1^{\mathrm{a}} \\
{ }^{\mathrm{ab}} \mathrm{HQ} 427046.1^{\mathrm{b}}\end{array}$ \\
\hline
\end{tabular}

${ }^{\mathrm{a}}=$ sequences from GenBank psbA-trnH, ${ }^{\mathrm{b}}=$ sequences from GenBank atpB-rbcL,

${ }^{\mathrm{c}}=$ sequence from GenBank, ${ }^{\mathrm{ab}}=$ sequences used as an outgroup,

$-=$ no information about the specimen

\section{Cluster analysis}

The phylogenetic tree based on combined chloroplast DNA (cpDNA) and sequence of 18 Eriobotrya names with $M$. germanica, $R$. indica and $P$. beauverdiana as an outgroup was constructed by the ML method. The results revealed that the Eriobotrya phylogenetic tree could be divided into 4 groups (Figure 1). E. bengalensis, E. bengaensis var. angustifolia and E. obovata were clustered into clade A. E. deflexa, E. fragrans and E. seguinii formed clade B. E. japonica, E. malipoensis and $E . \times$ daduheensis clustered into clade C. Whereas the remaining names clustered into clade $\mathrm{D}$. Clade D was further divided into 4 subclades.
Subclade I included E. fusca, E. cavaleriei and E. tengyuehensis. Subclades II included only E. condaoensis. Subclade III included E. serrata and E. hookeriana. Subclade IV included E. petiolata, E. salwinensis and E. elliptica.

\section{DISCUSSION}

In the past, a variety of molecular markers such as nrDNA ITS, $a d h$ sequences and genome-wide RAD sequence were used to evaluate the species relationship of Eriobotrya (Yang et al. 2017). The chloroplast rbcL and trnL-trnF sequences were used to evaluate the phylogenetic property of Eriobotrya (Li et al. 2011), but the results could 


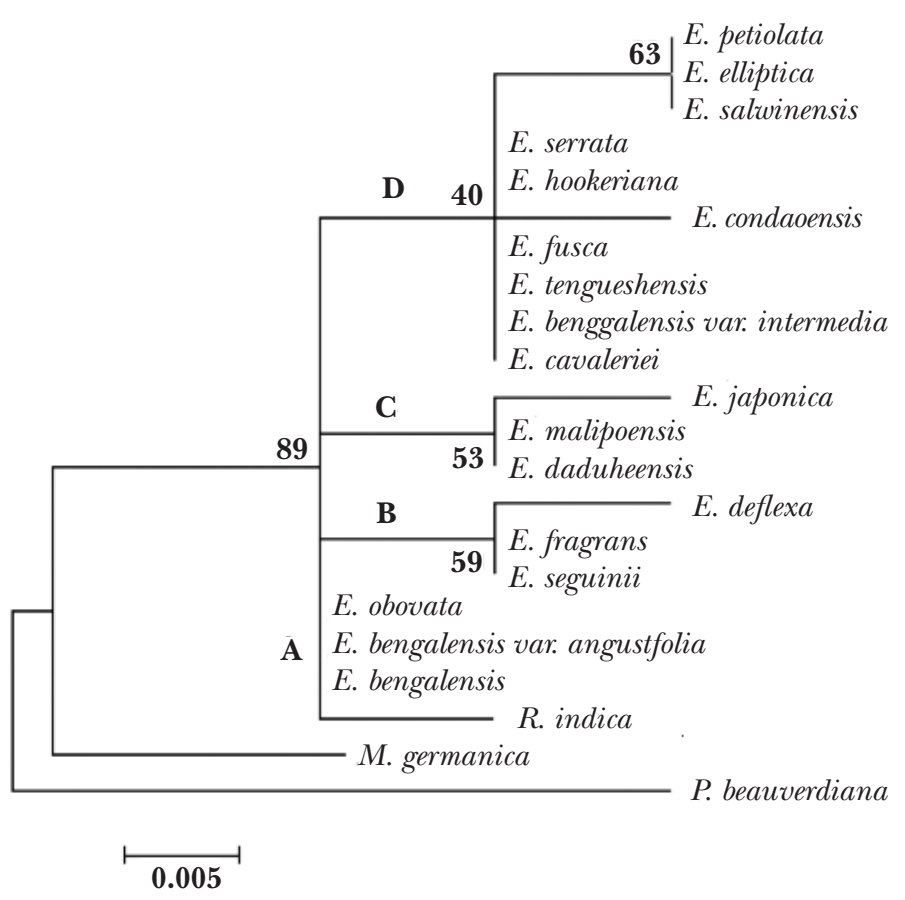

Figure 1 Maximum likelihood tree illustrating the phylogeny of the genus Eriobotrya based on cpDNA psbA-trnH and atpB-rbcL datasets.

not resolve the species relationships. The noncoding region between psbA-trnH and atpB-rbcL was used in phylogenetic studies in other important plant species such as Cyathea spp. and Aquilaria hirta (Balkrishna et al. 2020, Mohd Syafik et al. 2020) and recommended the use of the non-coding region as a promising plant DNA barcoding marker for various plant comparative studies (China Plant BOL Group 2011).

In the current study, we assessed the utility of two chloroplast DNA (psbA-trnH and atpB-rbcL) for identifying 21 Eriobotrya names, with $M$. germanica, $R$. indica, and $P$. beauverdiana as an outgroup using the maximum likelihood method. The phylogenetic tree produced, divided the Eriobotrya names into four clades. E. bengalensis, E. bengalensis var. angustifolia and E. obovata formed a group, which is largely consistent with previous studies (Yang et al. 2017, Zhang et al. 2017). Previous studies reported that E. maliopensis formed a separate clade and was genetically different from the rest of the species, and concluded that further studies should be needed to confirm its phylogenetic relationships (Yang et al. 2012). Findings from this study confirms the position of $E$. maliopensis and close relationship with E. japonica, E. malipoensis and $E . \times$ daduheensis, which is consistent with earlier studies on Eriobotrya (Yang et al. 2012, Zhang et al. 2017). Li et al. (2009) and Yang et al. (2012) revealed that E. cavalerie $i$ was classified to be a variety of $E$. fragrans. The present study showed that $E$. fragrans had close relationships with $E$. deflexa and E. seguinii to formed a clade, whereas E. cavaleriei formed a clade and close relationship with E. tengyuehensis and E. fusca. Our results confirmed the position of both species and treated to be distinct species, as reported in our previous nrDNA ITS analysis (Idrees et al. 2020a). Some Eriobotrya species were not previously reported and their close relationships with other species were unknown. E. petiolata formed a clade with E. elliptica and E. salwinensis and had close relationships with each other. E. hookeriana was closely related to E. serrata. E. bengalensisvar. intermedia had a close relationship with E. cavaleriei, E. tengyuehensis, and E. fusca. E. condaoensis formed a long branch and made a distinct clade, which was consistent with our previous analysis on nrITS sequence (Idrees et al. 2020a).

The phylogenomic analysis by Liu et al. (2020) revealed that Rhaphiolepis and Eriobotrya strongly supported the paraphyly of Eriobotrya, with Rhaphiolepis nested within it and Eriobotrya was embedded in Rhaphiolepis. Shaw (2020) conserved the name Eriobotrya against Rhaphiolepis and concluded that the epithet japonica was 
preoccupied and the name of the panglobal loquat changes both in its genus and specific epithet. The replacement name Rhaphiolepis loquata (Liu et al. 2020) was superfluous and thus inadmissible because the cited synonym Crataegus bibas (Loureiro 1790), provided a prior available epithet that was unoccupied. Furthermore, new species continue to be described in Eriobotrya including E. condaoensis (Idrees et al. 2018), E. capitata (Averyanov 2019), E. laoshanica (Chen et al. 2020) and E. fusca (Idrees et al. 2020b). Presently, Eriobotrya and Rhaphiolepis are widely accepted globally in flora and horticulture references.

The two genera can be distinguished from each other by the following morphological characters; the primary lateral veins reaching at the leaf margin, often in a tooth (Craspedodromous) in Eriobotrya, whereas the primary veins consistently end without reaching the margins (Camptodromous) in Rhaphiolepis; the inflorescence are paniculate in Eriobotrya and racemose in Rhaphiolepis; flower white and carpels (2 or) 3-5 in Eriobotrya, whereas flower pink and carpels ) (-1) 2 in Rhaphiolepis; the sepals are persistent on the fruits in Eriobotrya, while in Rhaphiolepis, the sepals are early deciduous, leaving an annular ring at the summit of the fruit (Gu \& Spongberg 2003).

\section{CONCLUSIONS}

The present finding based on combined chloroplast DNA markers, psbA-trnH and atpB-rcbcL produced similar results obtained in previous analysis of phylogenetic relationships of Eriobotrya based on ITS sequences. However, the complete phylogeny and the interspecies relationship is still unclear and difficult to determine, due to the lack of specimens from Southeast Asia including Vietnam, Malaysia and Myanmar. Further research will be necessary to include more taxa of Eriobotrya and the use of more DNA barcode markers to provide a more comprehensive and complete phylogeny and evolution of Eriobotrya.

\section{ACKNOWLEDGMENTS}

The authors would like to thank the curators of the CENT, IBSC, KUN, PE, SCAU and SYS Herbarium for their assistances in the specimen studies and also to the reviewers for their helpful comments. This work was supported by Ministry of Science and Technology of China; Science and Technology Basic Work, National Natural Science Foundation of China; Major Scientific and Technological Achievements Transformation Project of Neijiang Normal University, Scientific Research Project of Neijiang Normal University and National Survey of Traditional Chinese Medicine Resources Project of National Administration of Traditional Chinese Medicine.

\section{REFERENCES}

Averyanov LV. 2019. Rosaceae. Pp 118-119 in Averyanov et AL. (eds) Plant diversity, flora and vegetation of Hin Nam No National Protected Area: plant communities and plant species diversity of Hin Nam No National Protected Area. Lap Lambert Academic Publishing, Laos.

Balkrishna A, Arya V \& Kushwaha AK. 2020. Population structure, regeneration status and conservation measures of threatened Cyathea spp. Journal of Tropical Science 32: 414-421. doi: 10.26525/ jtfs2020.32.4.414

Campbell CS, Evans RC, Morgan DR et al. 2007. Phylogeny of subtribe Pyrinae (formerly the Maloideae, Rosaceae): limited resolution of complex evolutionary history. Plant Systematics and Evolution 266: 119-145. doi: 10.1007/s00606-007-0545-y

Chen SF, Meng KK, Guo XB et AL. 2020. A new species of Eriobotrya (Rosaceae) from Yunnan Province, China. Phytokeys 146: 61-69. doi: 10.3897/ phytokeys.146.50728

China Plant Bol Group. 2011. Comparative analysis of a large dataset indicates that internal transcribed spacer (ITS) should be incorporated into core barcode for seed plants. Proceeding of the National Academy of Science of the United States of America 108: 19641-19646. doi: 10.1073/pnas.1104551108

Gu SZ \& SpOngberg SA. 2003. Eriobotrya Lindley. Transactions of Linniean Society of London 1821, 13: 96, 102. Flora of China 9: 131-141.

HALL TA. 1999. BioEdit: a user-friendly biological sequence alignment editor and analysis program for window 95/98/NT. Nucleic Acids Symposium Series 41: 95-98.

Idrees M, Troung VD \& GaO XF. 2018. A new species of Eriobotrya from Con Dao National Park, southern Vietnam. Phytotaxa 365: 288-294. doi: 10.11646/ phytotaxa.365.3.6

Idrees M, Akash T, Mitra LP et al. 2020a. Phylogenetic relationships of the genus Eriobotrya (Rosaceae) based on Nuclear Ribosomal DNA (ITS) Sequence. Pakistan Journal of Botany 52: 1679-1684. doi: 10.30848/PBJ2020-5(11)

Idrees M, Mitra LP \& GaO XF. 2020b. Eriobotrya fusca sp. nov. (Rosaceae) from Yunnan Province, China. Bangladesh Journal of Botany 49: 1077-1084.

Larkin MA, Blackshielfs G, Brown NP et al. 2007. Clustal $\mathrm{W}$ and Clustal $\mathrm{X}$ version 2.0. Bioinformatics 23: 2947-2948. 
Li P, Lin SQ, YAng XH et AL. 2009. Molecular phylogeny of Eriobotrya Lindl. (loquat) inferred from internal transcribed spacer sequences of nuclear ribosome. Pakistan Journal of Botany 41: 185-193.

Li P, Yang XH, Hu GB et al. 2011. A preliminary phylogenetic study of Eriobotrya based on cpDNA rbcL and trnL-F sequences. Acta Horticulturae 887: 79-83. doi: 10.17660/ActaHortic.2011.887.11

LINDLEYJ. 1821. Observation on the natural group of plants called Pomaceae. Transaction of the Linnean Society of London 8: 102.

Liu BB, Liu GN, Hong DY et AL. 2020. Eriobotrya belongs to Rhaphiolepis (Maleae, Rosaceae): evidence from chloroplast genome and nuclear ribosomal DNA data. Frontiers in Plant Science 10: 1731 doi: 10.3389/ fpls.2019.01731

Loureiro J DE. 1790. Classis XII. Icosandria. Monogynia. Pp 304-325 in Loureiro J DE (eds) Flora Cochinchinensis. Typis et Expensis Academicis, Lisbon. doi: 10.5962/ bhl.title. 560

Mohd Syafik MH, Che Mohd Aizal CM, Siti Hajar NS et AL. 2020. Characterisation of Aquilaria hirta based on morphological evaluation and volatile chemical compound. Journal of Tropical Forest Science 32: 289 295. doi: $10.26525 / \mathrm{jtfs} 2020.32 .3 .289$

Potter D, Eriksson T, Evans RC et al. 2007. Phylogeny and classification of Rosaceae. Plant Systematics and Evolution 266: 5-43. doi: 10.1007/s00606-007-0539-9

SANG T, Crawford DJ \& Stuessy TF. 1997. Chloroplast DNA phylogeny, reticulate evolution, and biogeography of Paeonia (Paeoniaceae). American Journal of Botany 84: 1120-1136. https://doi.org/10.2307/2446155

Savolainen VM, Manen JF, Douzery E et al. 1994. Molecular phylogeny of families related to Celastrales based on rbcL 5' flanking sequences. Molecular Phylogenetics and Evolution 3: 27-37. https://doi.org/10.1006/ mpev.1994.1004

Sun JH, Shou S, Li JL et al. 2018. Phylogeny of Maleae (Rosaceae) based on multiple chloroplast regions: implications to genera circumscription. BioMed Reseach International. Volume 2018. Article ID 7627191. doi.org/10.1155/2018/7627191
SHaw JMH. 2020. Proposal to conserve the name Eriobotrya against Rhaphiolepis (Rosaceae). Taxon 69: 620. doi: 10.1002/tax.12272

Tamura K, Stecher G, Peterson D et al. 2013. MeGA6: Molecular Evolutionary Genetic Analysis Version 6.0. Molecular Biology and Evolution 30: 2725-2729.

VIDAL JE. 1965. Notes sur quelques Rosacées asiatiques (III). Révision du genre Eriobotrya (Pomoideae). Adansonia 5: 551-576.

XIE JH, YANG XH \& Lin SQ. 2007. Analysis of genetic relationships among Eriobotrya germplasm in China using ISSR markers. Acta Horticulturae 750: 203-208. doi: 10.17660/ActaHortic.2007.750.31

YANG XH, GLaKPe K, Lin SQ ET AL. 2005. Taxa of plants of the genus Eriobotrya around the world and native to Southeastern Asia. Journal of Fruit Sciences 22: 55-59.

YANG XH \& LiN SQ. 2007. New ideas on the classification of loquat. South China Fruits 36: 28-31.

YANG XH, LiU CM \& LIN SQ. 2009. Genetic relationships in Eriobotrya species as revealed by amplified fragment length polymorphism (AFLP) markers. Scientia Horticulturae 122: 264-268. doi: 10.1016/j. scienta.2009.04.012

YANG XH, Li P \& ZHANG ZK. 2012. A preliminarily phylogeny study of the Eriobtorya based on the nrDNA adh sequences. Notulae Botanicae Horti Agrobotanici ClujNapoca 40: 233-237. doi: 10.15835/nbha4027997

Yang XH, NaJafabadi SK, Shahid MQ et al. 2017. Genetic relationships among Eriobotrya species revealed by genome-wide RAD Sequence data. Ecology and Evolution 7: 2861-2867. doi: 10.1002/ece3.2902

Yu TT. 1974. Flora Reipublicae Popularis Sinicae. 36. Science Press, Beijing.

Zhang HZ, Peng SA, Cai LH et al. 1990. The germplasm resources of the genus Eriobotrya with special reference on the origin of E. japonica Lindl. Acta Horticultureae Sinica 17: 5-12.

Zhang Z, Guifen L, Xianghui Yet al. 2017. Taxonomic studies using multivariate analysis of Eriobotrya based on morphological traits. Phytotaxa 302: 122-132. 